Acta Poetica $26(1-2)$

PRIMAVERA-OTOÑ

2005

\title{
El sentido y los sentidos en la oralidad náhuatl prehispánica
}

\author{
Patrick Johansson
}

La expresión oral prehispánica (o de inspiración prehispánica) fue recopilada y transcrita en el siglo XVI por los españoles, como parte de una estrategia catequística que buscaba conocer al Otro para evangelizarlo mejor. Lo "malo" y lo "fuera de tino" desde la perspectiva cristiana, fue omitido. La captación exclusiva del componente verbal de los textos orales indígenas en un manuscrito, además de despojarlo de elementos imprescindibles para su expresión y recepción plenas, asignó a la palabra un papel trascendental que no tenía en su contexto prehispánico, lo que los empobreció. Por ello, en este artículo propongo diferentes estrategias para reconstituir la profusión semiótica de los textos provenientes de la oralidad mexicana precolombina.

During the xvith century, oral prehispanic literature was written down by Spanish priests as a religious strategy to know better the Other. Texts were transcribed according to priests criteria, who decided on the contents. They kept from oral utterances what they considered "good" and the "wrong" was eliminated. Although writing preserved prehispanic texts from loss, all the alterations they suffered, also transformed our knowledge of them. Writing down oral texts also implied impoverishing them. On one hand all the musical and gestual elements of the performance were excluded; on the other, the main role taken by the written word did not belong to the prehispanic context. In this paper, I will propose several strategies to recreate Mexican prehispanic oral texts in a multi-layered semiotic context. 
Patrick Johansson

Instituto de Investigaciones Históricas, UNAM

\section{El sentido y los sentidos}

\section{en la oralidad náhuatl prehispánica}

Recopilada y transcrita en el siglo XVI por los españoles, como parte de una estrategia catequística que buscaba conocer al Otro para evangelizarlo mejor, la expresión oral prehispánica (o de inspiración prehispánica) sufrió por este transvase a un contenedor gráfico-alfabético, si bien una parte sustancial de ella fue salvada del olvido.

Lo "malo" y los "fuera de tino", 1 en la perspectiva cristiana, fue destruido después de haber sido debidamente "refutado", mientras que lo "bueno", en esta misma perspectiva, se conservaba y transcribía de nuevo en manuscritos especialmente elaborados para alojarlo. Entre los textos "buenos" conservados, algunos fueron despojados de sus alusiones paganas, y a veces interpolados para que el cauce del torrente expresivo indígena, sutilmente desviado, pasara por el molino evangelizador, o que dichos textos se cantaran, bailaran o recitaran sin perjuicio para la religión recién establecida. Algunos textos considerados por muchos como "peligrosos" para la propagación de la Fe fueron, sin embargo, conservados gra-

${ }^{1}$ Cf. Mendieta 1980, 75. 
cias al empeño humanista del recopilador, como en el caso del franciscano fray Bernardino de Sahagún, o al ingenio travieso de algunos auxiliares y escribas indígenas que lograron burlar la censura eclesiástica.

Integrado a un contexto específico que justificaba su enunciación, un texto oral náhuatl prehispánico estaba hecho de palabras, gestos, colores, pinturas faciales, indumentaria y eventualmente música y danza que se fundían en el crisol de una circunstancia particular de enunciación o de canto para forjar un sentido. En su transcripción al alfabeto no se pudo rescatar más que la parte verbal de un complejo tejido expresivo.

La captación exclusiva del componente verbal de un texto oral indígena en un manuscrito, además de despojarlo de elementos imprescindibles para su expresión y recepción plenas, asignó a la palabra un papel trascendental que no tenía en su contexto prehispánico. El embudo alfabético en el que fue colado el texto oral en el momento de su transcripción, propició asimismo una linealidad sintagmática ajena a su expresividad propia, a la vez que confería al semantismo de la palabra un valor trascendental.

El sentido "gráfico" del texto surgió entonces de la configuración gramatical de unidades lingüísticas en vez de brotar de una totalidad plurisemiótica mediante una movilización de los sentidos. En este contexto, uno de ellos: la vista, desplazaba a los demás en la construcción del sentido a la vez que la abstracción conceptual se imponía a la cognición sensible.

Ahora bien, nos debemos preguntar qué percepción y subsecuente fruición puede tener, hoy, el lector de un texto oral náhuatl transcrito en el siglo XVI mediante una recopilación que si bien lo salvaba del olvido no permitía su recepción integral. 


\section{Oralidad y pensamiento}

La oralidad náhuatl prehispánica es estética en el sentido etimológico de la palabra: busca hacer sentir más que dar a entender lo que expresa. ${ }^{2}$ Esta oposición aparente entre dos modalidades específicas de producir, transmitir y recibir sentimientos e ideas sugiere que se consideren algunos aspectos cognitivos de la oralidad náhuatl antes de evocar las circunstancias, los contextos y las modalidades expresivas que la caracterizan.

\subsection{La palabra y el sentido}

Entre los distintos lenguajes de los que dispone el hombre para vincularse con sus semejantes y más generalmente con el mundo, destaca sin duda el lenguaje verbal. Éste constituye inclusive para muchos, el único medio de procesar, en términos cognitivos, la pluralidad fenoménica del mundo. En El arco y la lira, Octavio Paz escribió:

No hay pensamiento sin lenguaje, ni tampoco objeto de conocimiento: lo primero que hace el hombre frente a una realidad desconocida es nombrarla, bautizarla. El hombre es un ser de palabras. (Paz 1981, 45)

En esta aseveración, el poeta pone énfasis sobre la trascendencia del semantismo verbal y el carácter objetivante del lenguaje así configurado. La relación entre las palabras y las cosas fue expresada, sin embargo, de manera distinta por otros poetas y literatos que cuestionaron la capacidad que tienen las primeras para referir o construir un sentido pleno y denunciaron, como lo hizo el dramaturgo francés Gaston Baty, la "tiranía de su señoría la palabra".

En efecto, si la aparición del lenguaje verbal, culminación de una lenta evolución de las facultades cognitivas del Homo sa-

\footnotetext{
${ }^{2}$ La etimología griega de aestheticos es, originalmente, "lo que permite sentir".
} 
piens, consagró al hombre como tal, la palabra no tiene, sin embargo, la exclusividad de la expresión, transmisión y recepción de ideas y sentimientos. Existen otros medios, más entrañablemente vinculados con el ser, más "somáticos", los cuales, sin excluir la palabra, permiten una aprehensión afectivo-cognitiva del mundo evitando asimismo que se establezca una ruptura entre el hombre y su entorno. Si "nombrar" una realidad desconocida, como lo afirma Octavio Paz, es sin duda una tendencia cognitiva típicamente humana, el concepto que resulta de este procesamiento eidético puede alejar al hombre del mundo, sobre todo cuando dicho hombre, con el tiempo, acentúa la abstracción conceptual en detrimento de la cognición sensible.

Por otra parte, la aprehensión cognitiva del mundo conlleva también una objetivación del ente por conocer, mediante una abstracción de su contexto, un desprendimiento de una totalidad inmanente. Lo que se busca conocer es parte de un todo pero los límites que definen esta "parte" son de índole cultural, artificial (en el mejor sentido de la palabra), y constituyen a veces contenedores impermeables que no dejan fluir el sentido. En este contexto, hablar de algo no permite coincidir con este "algo", por lo que las comunidades humanas intentaron "incorporar" lo que decían o lo que querían aprehender para sentirlo, más que conocerlo en términos abstractos.

Si, como lo señalamos adelante, el pensar está estrechamente vinculado con el sentir en el conocimiento indígena, la instrumentación del saber no se limitará a una aprehensión verbal de la realidad sino que buscará medios más adecuados a sus afanes sensibles de cognición. La abstracción conceptual que permiten las palabras se vuelve, en este contexto, un obstáculo para la aprehensión plena de una realidad y para lograr una simbiosis cognitiva con el mundo. A la nítida trascendencia del saber conceptual, la sabiduría indígena prefería la difusa inmanencia de un saber sensible, profundo, fibroso, somático. 
Fuera de los ámbitos técnicos, la estructuración, conservación y transmisión del saber indígena, se realizaba mediante la palabra, sin duda, pero también a través de la danza, los gestos emblemáticos, la indumentaria, la imagen, sabores y aromas, movilizando los cinco sentidos, para que fraguara mejor el sentido.

\subsection{El decir de la palabra oral}

En circunstancias orales de elocución, la palabra se encuentra integrada en un aparato expresivo suprasegmental: miradas, gestos, altos y bajos de la voz, el timbre, presencia física de los participantes, etcétera, lo que merma la trascendencia de su semantismo propio y deja a los parámetros modales una importancia toral en la estructuración del sentido. La palabra está estrechamente vinculada con la circunstancia espacio-temporal y la demanda socio-cultural que la suscitan. La palabra alimenta el cuerpo colectivo en momentos, y de manera específica, mediante verdaderos torrentes verbales sin "compuertas" ni "esclusas" que puedan detener su ímpetu. En este contexto, lo que se dice, no es más que un aluvión en un flujo del decir que sacia la sed de ubicación existencial de una colectividad humana. Como nunca se detiene el decir en lo dicho, no se decanta el aluvión: fluye el texto.

La extrema funcionalidad del decir oral indígena hace que cada texto produzca un efecto más que un sentido, o mejor dicho: el sentido determina un efecto. La palabra indígena es ante todo performativa. El canto de guerra es más guerra que canto: el canto de cacería es más determinante para las actividades cinegéticas que la puntería del cazador, el canto "travieso" propicia la fertilidad de la tierra, el canto mortuorio de lamentación exacerba catárticamente el dolor con palabras-harapos, ${ }^{3}$ des-

\footnotetext{
${ }^{3}$ Los cantores que elevaban, en contextos mortuorios, los cantos de lamentación, tlaocolcuícatl se vestían de harapos sucios, connotando asimismo la suciedad y el desgarre anímico que trae consigo la muerte de un ser querido. Cf. Johansson 2002, 221-222.
} 
garradas, como los seres que la profieren. Aun en contextos más referenciales, la palabra es performativa.

Basta con recordar algunos testimonios indígenas de la conquista recopiladas por los españoles para convencerse de ello. La palabra que evoca un hecho histórico, real, más que referirlo objetivamente, busca revivirlo mediante una estrategia discursiva que genera un efecto. La descripción de la llegada a México del ejército español por un informante de Sahagún es una prueba fehaciente de ello. El "bullicio" textual y la efervescencia de sentido sensible que produce la narración en el texto original contrastan con la precisa, pero fría referencia que hace Sahagún del acontecimiento. ${ }^{4}$

En la oralidad náhuatl el decir nunca moría en lo dicho, ni el sentir en lo comprendido.

\section{Saber indígena y oralidad}

A diferencia del conocimiento de corte occidental heredado de la mayéutica helénica, el saber indígena prehispánico, necesariamente objetivante como cualquier cognición humana, buscaba sin embargo una aprehensión sensible del objeto por conocer. Buscaba "comulgar" afectivamente con dicho objeto para lograr su aprehensión plena. Analizaremos brevemente, a continuación, los términos y los conceptos nahuas referentes al conocimiento que atañen de alguna manera a la oralidad.

\subsection{Tlamati: saber y sentir}

Los textos indígenas, ya sean verbales o pictóricos, muestran una estructuración del sentido donde lo sensible y lo formal ocupan un lugar preponderante. Se trata no sólo de comunicar

\footnotetext{
${ }^{4}$ Cf. Johansson 1999, 209 y ss.
} 
algunos contenidos o de compartir ideas abstractas sino de "con-mover", en el sentido etimológico de la palabra, al receptor de un mensaje para lograr una adhesión participativa a lo que se transmite. En este contexto, la esfera específica de recepción y procesamiento del texto no será únicamente el intelecto sino la totalidad del ser sensible.

En el mundo precolombino, un mensaje no se consideraba como comprendido hasta que fuera sentido. El hecho de que en náhuatl un mismo significante mati cubra campos semánticos para nosotros tan distintos como "saber" y "sentir" es una prueba fehaciente de ello. Es además, interesante observar que, sin que esto represente una metáfora, el discurso indígena sitúa el entendimiento en órganos asociados con la sensibilidad.

\subsection{La abstracción}

Como lo demuestra la etimología de la palabra que la refiere, la noción de "abstracción" remite al hecho de "traer fuera" algo que estaba "dentro", cuando este algo: la idea, estaba entrañablemente vinculada con una cosa, un hecho, o una acción específicos. Es decir que entre más abstracto es el pensamiento más se aleja de las cosas tangibles y de los hechos manifiestos.

Todo parece indicar que el pensamiento indígena no favorecía mucho la "ab(s)-tracción" eidética, y la subsecuente elucubración conceptual como eje de su conocimiento. El hecho de que la sensación tuviera que estar presente, de alguna manera, en la configuración cognitiva que el indígena tenía de algo, hacía que la idea "hiciera cuerpo" con lo que intentaba representar. En este contexto, lo simbólico, o mejor dicho lo "símbolo-lógico", las afinidades visuales o sonoras, la "simbiosis" semántica de las palabras, la retórica y la poesía permitían al saber cristalizarse sobre la palabra de los hombres. 
Tlalnamiqui: recuerdo luego pienso

Si bien evolucionó a lo largo de la historia, adaptándose a los determinismos de cada época, la cognición indígena no tuvo el carácter especulativo que tiene la cognición occidental. Por muy sabios que fueran los tlamatinime nunca pusieron en tela de juicio lo que "habían dicho los abuelos", ni siquiera lo comentaban como lo hicieran los escolásticos medievales europeos con los textos de Aristóteles.

Siendo el pasado la matriz del presente y del futuro, los textos que se gestaron un día para responder a una demanda cognitiva específica, tienen un carácter casi sagrado que los protege de las embestidas inquisitorias que podrían surgir de una situación existencial determinada. "Lo que dijeron los abuelos" es un dixit Magister inapelable, sometido a la erosión cultural del tiempo mas no a la especulación de los hombres.

Más allá de la enseñanza, de la tinta roja y negra (tlilli, tlapalli), que dejaron los abuelos y que permite "pensar" en el sentido indígena del concepto, el hecho de recordar atañe a la dimensión pretérita de la existencia, a la memoria, la cual funge, en el mundo indígena precortesiano, como una verdadera matriz del presente y del futuro y, por tanto, muy probablemente, como el crisol donde se fragua la verdad.

Nemilía "pensar": proceder al acto de existir

El carácter polisintético de la lengua náhuatl que congrega los distintos lexemas y morfemas en verdaderos "racimos" verbales permite observar la construcción del sentido desde sus etapas primitivas, antes del discurso, en la gramática misma de dicha lengua.

Una de las palabras que expresa el acto de pensar: nemilía, se compone del radical nemi provisto del morfema aplicativo 
-lía. Ahora bien nemi es "existir", por lo que el compuesto verbal que refiere el hecho de pensar significaría originalmente "proceder al acto de existir".

La relación estrecha entre el acto de pensar y el de existir evoca, curiosamente, el postulado cartesiano "pienso luego existo", el cual constituye, según el filósofo francés del siglo XVII, una prueba ontológica de la existencia. El sentido implícito de la palabra náhuatl que vincula etimológicamente la existencia y el pensamiento, nada tiene que ver con la prueba lógica de la existencia del ser pensante que buscaba Descartes, ya que el pensamiento indígena no necesitaba "pruebas" de la tangibilidad ontológica de su ser. Sin embargo expresa claramente que la existencia está estrechamente vinculada con el pensamiento. La luz de la inteligencia acompaña el andar existencial, exactamente como el sol brilla durante su recorrido del este al oeste antes de desaparecer en el inframundo.

Nenoyolnonotza "dialogar con el corazón": la reflexión

Tanto la competencia lingüística como el uso discursivo de las palabras que aluden al raciocinio indican que los antiguos nahuas consideraban el corazón como un lugar privilegiado de la reflexión. Las expresiones "conversar con su corazón” (ne)yolnonotza, "llegarle (respecto de algo) al corazón" (yolmaxiltía) o más sencillamente "hacer uso del corazón" (yolloa) sugieren que el corazón, más que la mente, fungía como un "procesador" o un espejo de las ideas.

Por muy lógico y racional que fuera el cuestionamiento reflexivo, el pensamiento indígena lo concebía como un diálogo entre el intelecto y la sensibilidad, entre la mente y el corazón. Reflexionar era dialogar con su corazón neyolnonotza, es decir, en este contexto, fundir la argumentación intelectualmente configurada en el crisol de la sensibilidad. 
Omeyolloa "se parte en (o se hace) dos el corazón": la duda

El profundo arraigo del conocimiento en la dimensión sensible del indígena excluye la duda como un método para alcanzar la verdad. La verdad es algo sutil, difuso, que atañe a la totalidad del ser y no sufre una fragmentación. En este contexto, la duda, piedra angular del pensamiento occidental, era percibida como una ruptura, una disyunción, un extravío y, en última instancia, una pérdida de la verdad.

La connotación de la palabra náhuatl que refiere este concepto ome yolloa literalmente "hacerse dos el corazón" o "(dividirse en) dos el corazón" revela la diferencia que puede haber entre la convicción plena que nace de una intuición cognitivo-afectiva única sin otra opción que se le oponga, y la división con el desdoblamiento del corazón que genera la incertidumbre, el malestar, una ruptura entre el mundo y el conocimiento que el hombre tiene de él.

\section{Las "circun-stancias" de la expresión oral}

Lo circunstancial no tiene en el mundo náhuatl prehispánico el carácter eventual y accesorio que tiene en la cultura occidental contemporánea. En efecto, como lo revela la cosmología indígena, la "circun-stancia", etimológicamente "lo que está alrededor", es parte de una totalidad fenoménica que no distingue lo contingente existencial de lo esencial.

En lo que concierne a la expresión oral, la instancia de elocución o de canto estaba estrechamente vinculada con el espacio-tiempo en que se realizaba y los hechos socio-culturales que la enmarcaban. El texto, cualquiera que fuera su expresividad específica, estaba "arraigado" en el lugar y el momento de su enunciación.

La importancia del lugar y del momento en un acto elocutivo oral puede sorprender al lector contemporáneo acostumbrado a 
leer textos cuyo semantismo trasciende, generalmente, estos determinismos. En efecto, el hecho de leer un texto alfabético en un lugar $\mathrm{u}$ otro, en un momento $\mathrm{u}$ otro, si bien puede determinar un nivel óptimo o pésimo de concentración, no afecta generalmente los mecanismos de producción de sentido y la subsecuente recepción de dicho texto. En cambio, en la oralidad náhuatl prehispánica, el lugar y el momento son partes constitutivas de un vasto tejido expresivo: el texto oral.

\subsection{El espacio}

Los espacios propios de la realidad náhuatl prehispánica son esencialmente de dos tipos: los espacios naturales, donde la epifanía formal del relieve o de la vegetación revela los lugares predilectos del culto, y los espacios creados, que traen la naturaleza a la urbe por una parte, y por otra delimitan netamente los límites que separan el espacio sacro de lo profano.

La Tierra, madre de los pueblos mesoamericanos, era adorada bajo las múltiples formas que exhibía su topografía: montes, cuevas, quebradas, bosques, llanos, ríos y lagunas eran epifanías naturales que envolvían el acto expresivo y le conferían un sentido.

Los espacios creados por el hombre cualquiera que fuera su índole arquitectónica, definían también espacios sagrados que modalizaban de cierta manera el discurso oral que ahí se enunciaba. Fray Bernardino de Sahagún describe un rito altamente teatral que se realizaba en el marco de la fiesta Etzalcualiztli dedicada a los tlaloques, dioses asociados con las lluvias, en una extensión de agua rodeada de cuatro casas llamadas ayauhcalli, "casa de niebla":

Estaban estas casas ordenadas hacia las cuatro partes del mundo, una hacia oriente, otra hacia el septentrión, otra hacia el poniente, otra hacia el mediodía. 
El primer día se metían todos en una de éstas; el segundo, en la otra; el tercero, en la tercera; y el cuarto, en la cuarta; [...] estando así, comenzaban de hablar uno de los sátrapas que se llamaba Chalchiuhquacuilli y decía: cóatl izomoyocan móyotl icauacayan, atapálcatl innechiccanauayan, aztapilcue cuetlacayan, que quiere decir éste es lugar de culebras, lugar de mosquitos, y lugar de patos, y lugar de juncias.

En acabando de decir esto el sátrapa, todos los otros se arrojaban en el agua con los pies y con las manos, haciendo gran estruendo, comenzaban a vocear y a gritar, y a contrahacer las aves del agua; unos a los ánades, otros a unas aves zancudas del agua que llaman pipitzin, otros a los cuervos marinos, otros a las garzotas blancas, otros a las garzas. $(1997,115)$

El juego de pelota polarizaba asimismo lo sacro a la vez que definía un espacio-tiempo circunstancial estructurante para los ritos que se escenificaban.

Cada trinquete era templo, porque ponían las imágenes del dios del juego y de la pelota, encima de las paredes más bajas, a la media noche de un día de buen signo con ciertas ceremonias y hechicerías, y en medio del suelo hacían otras tales, cantando romances y canciones que para ello tenían. (Torquemada 1992, IV, 343)

La incidencia del espacio sobre lo que se dice podía afectar los contenidos. Cuando Motecuhzoma Xocoyotzin aterrado por la llegada de los españoles recibió a los mensajeros que había mandado a la costa, no quiso oír las nuevas que traían en cualquier lugar: lo hizo en el templo Coacalco, dedicado a los dioses foráneos ${ }^{5}$ esperando que la sacralidad de espacio pudiera influir sobre el mensaje y cambiar su destino.

\footnotetext{
${ }^{5}$ Códice Florentino (1979), libro, XIII, capítulo 6.
} 


\subsection{El tiempo}

Así como el espacio constituía una verdadera matriz escenográfica de la expresión oral, el tiempo determinaba la performatividad de lo que se estaba expresando a la vez que ayudaba a formalizarlo contextualmente mediante una red compleja de símbolos que atañían a los ciclos naturales y calendáricos. Un texto cantado a la media noche en una cueva, en el solsticio de invierno, se impregnaba de sentido telúrico-materno mientras que otro, elevado al mediodía en la cima de un monte, en el solsticio de verano, adquiría un tenor uranio y masculino. La aprehensión sensible de dichos textos en sus contextos y circunstancias específicos permitía una recepción plena de lo que se quería transmitir.

\section{El “con-texto"}

Según el género expresivo considerado, la oralidad náhuatl prehispánica se integraba a "con-textos" culturales que salían del ámbito propiamente discursivo y atañían a actividades diversas. Los hilos de la trama verbal se urdían entonces con otros elementos expresivos o contextuales para tejer un sentido global. Como la etimología de la palabra lo indica, un "con-texto" es parte constitutiva del texto. Si bien en la cultura occidental, no pasa de ser un marco general en que se inscribe el texto, en la cultura náhuatl prehispánica, el contexto determina en gran parte el valor del texto.

La lectura de un texto oral transcrito no puede prescindir, por tanto, de su contextualización, cuando las fuentes disponibles permiten realizarla. En efecto, una palabra, una frase o un párrafo pueden integrarse a una actividad específica sin dejar por esto de tener un valor "literario". Una lectura que teje palabras, frases y párrafos entre ellos sin considerar los vínculos 
"con-textuales" que existen en cada nivel, puede resultar totalmente errónea. Para ilustrar lo anterior aduciremos a continuación el ejemplo de un canto de cacería.

—Aamicuícatl "canto de la(s) flecha(s) de cacería"

Un canto oral "almacenado" en forma alfabética en un apéndice del libro II del Códice Florentino 6 y que se puede leer en su versión original náhuatl en menos de un minuto, muestra de manera clara la importancia de "con-textualizar" un texto oral. En efecto, según lo reveló una investigación que realizamos, ${ }^{7}$ dicho texto se cantaba, bailaba y escenificaba a lo largo de varias horas o tal vez días, como parte del proceso de fabricación de las flechas que se iban a utilizar en la primera expedición cinegética del año, durante la fiesta Quecholli.

El primer renglón constituye una invocación de la diosa tierra sobre cuyo flanco ixillan Tonan se va a realizar la primera cacería: ${ }^{8}$

\section{Cotihuana cotihuana cali totochmanca Huiya ayya}

Cotihuana cotihuana, vientre de la tierra

El dístico siguiente se cantaba y bailaba repetidamente en el patio del templo de Huitzilopochtli quizás durante varios minutos, con las cañas que habían sido previamente enderezadas al fuego.

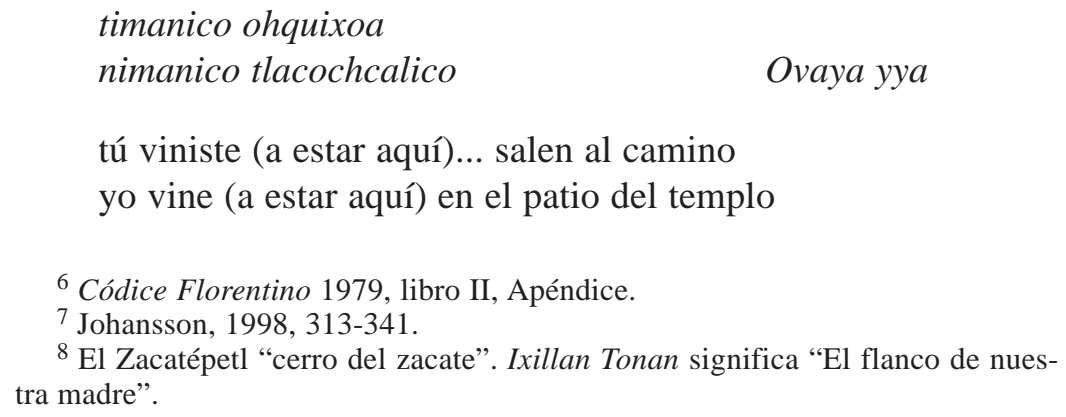


El verso siguiente acompañaba el gesto mediante el cual se colocaba la mariposa de obsidiana (itzpapálotl) sobre la caña:

ma tonica ma tonicatico

Párate (aquí), ven a pararte (aquí).

Comenzaba entonces un baile durante el cual se infundía un principio anímico a la flecha recién manufacturada a la vez que sus cualidades eran puestas a prueba.

Zana zana ayo huehca nivia.

Yya yya yevayya

Zana zana ayo huehca nivia

sólo, sólo, ayo, lejos voy

sólo, sólo, ayo, lejos voy

Las aliteraciones y las asonancias del texto verbal inducían verdaderamente las cualidades de sustento y velocidad de las flechas.

Un crescendo semántico-sonoro seguía, implicando a la futura presa, un pato:

\section{Ye nicuilihua Aya nihuaya nihuaya nihuaya a icanauh nihuaya nihuaya nihuaya a icanauh}

Ye yo la mando Aya me elevo ya me elevo ya me elevo ya $A$ su pato

me elevo ya me elevo ya me elevo ya $A$ su pato

Es probable que una mimesis músico-dancística escenificara lo anterior. La puntería de las flechas se propiciaba después mediante la armonía sugestiva de los siguientes versos:

Tla ixtotoca ye canauhtzin in tla ixtotoca ye canauhtzin in ye canauhtzin in. 
Síguele la pista a este patito

Síguele la pista a este patito

a este patito

Se percibe claramente en la prosodia del texto náhuatl trascrito el ritmo obsesivo-mágico del teponaztli.

El canto terminaba de manera apoteótica con la penetración de la flecha en el pato.

\section{Ahuiya Itzipan a momahuilia \\ Ahuiya Itzipan a momahuilia \\ Ahuiya Itzipan a momahuilia}

Ahuiya sobre la obsidiana se da gusto

Ahuiya sobre la obsidiana se da gusto

Ahuiya sobre la obsidiana se da gusto

Este microdrama músico-dancístico, además de ser una parte esencial del ritual de fabricación de las flechas, anticipaba un éxito en la cacería.

Se colige de lo anterior que una lectura descontextualizada de la parte verbal del Aamicuícatl "canto de la(s) flecha(s) de cacería", no podría haber restituido el sentido original y permitido una justa apreciación del texto oral transcrito.

Asimismo los cantos de guerra, cantos mortuorios, cantos eróticos, o los cantos que acompañaban las distintas labores agrícolas, los encantamientos mágicos, etcétera, establecían con sus "con-textos" específicos un sentido global inaprehensible con la sola lectura del registro verbal de dichos cantos.

\section{El sentido y los sentidos}

Fusión sinestésica de sonidos, de colores, de ritmos, de música, de fragancias, de gestos y de palabras, los cantos sagrados 
precolombinos no sólo permitían al indígena comunicar, sino comulgar con lo divino en la fragua festiva de un ritual.

Esta "ebriedad" polifónica en la que el verbo tenía que someterse al oleaje músico-dancístico, donde se alteraba significativamente el orden gramatical y aun morfémico de las palabras en aras de los movimientos sonoros del alma, permitía una aprehensión cognitiva sensible, casi "física", del mundo y propiciaba una acción "mágico-simpática” sobre él.

\subsection{La voz}

Antes de que se esculpa en ella el verbo, la voz tiene una materialidad y una expresividad propias. El cromatismo sonoro que constituye el timbre, la tonalidad, la acentuación, la intensidad, los altos y bajos, la articulación, la melodía, permiten configurar un sentido en ausencia de cualquier semantismo verbal.

Además de ser la sustancia sonora del lenguaje y del canto, la voz constituye un vínculo entre el hombre y el universo: se relaciona con el dinamismo fisiológico elemental: gritos del recién nacido, de guerra, de dolor o de alegría, y por lo mismo llegó a representar una manera de umbilicalismo mediante el cual la existencia se arraiga en su origen esencial: "La voz habita en el silencio del cuerpo como lo hizo el cuerpo en su matriz" (Zumthor 1983, 11).

La voz es lo que emerge de la intimidad del mundo por medio de la interioridad del cuerpo. Se exterioriza por la boca ( $o s$, oris = lugar del origen), pero nace en lo más profundo del cuerpo. Éste, a su vez, se asimila fisiológicamente al mundo de las cosas y el hombre siente esta voz que se eleva de lo más hondo de su ser como algo que se arranca a esta materialidad.

La imagen de la voz extiende sus raíces en una zona de lo vivido que escapa a las fórmulas conceptuales y que sólo se puede presentir: existencia secreta [...] con implicaciones de 
una complejidad tal que desborda todas sus manifestaciones particulares. (Zumthor 1983, 12)

Puede parecer algo aventurado tratar de evocar la voz náhuatl prehispánica cuando apenas su expresión verbal manuscrita llegó hasta nosotros; podemos sin embargo tener una idea de ella en las interjecciones que puntúan los versos de los cuicah. Estos cuicah ven sus segmentos verbales interrumpidos por vocalizaciones de tipo interjectivo y rítmico que tienden a frenar la pérdida de sustancia vocal que constituyó su expresión lingüísticamente pertinente. Es como si la fría estructuración de un sentido gramatical tuviese que ser reabsorbida inmediatamente por el calor rítmico de la voz. El sentimiento empañado de intelectualidad que se revela en el tejido verbal, tiene que culminar, explotar en una orgía vocal liberadora. La voz busca reabsorber la palabra prometeica en el caos vocal de su intimidad:

...imapan amoncate yn amontlatoa yeehuaya ohui ohui ilili $y$ yao ayyahue ito amaha ilili ahua y yao huia

(Cantares Mexicanos, 1994, fol. 10r).

...en su rama, ustedes están, ustedes hablan, yeehuaya ohui ilili yyao ayyahue ito amaha ilili ahua y yao huia.

Se observa generalmente en los textos:

- Una fuerte tendencia a la repetición obsesiva de patrones vocales, ya sean musicales o no, que podrían inclusive haber provocado trances.

Ohuaya ayya aya ohuaya

ohuaya ayya aya ohuaya

ohuaya...

- Bruscas síncopas en una continuidad determinada con cambio súbito de patrón rítmico. 
Nonohualico, Nonohualico, poyoma aya yyaya ayyo chimalocotitlan motlaquenhuia ayyo aya aya aya ayyo ah huetzin inin

Nonohualico cuahuinochitlan cacahuatla motlaquenhuia ah huetzin inin

(Sahagún 1997, 178)

En Nonohualco, en Nonohualco hay fragancias, aya yyaya ayyo

detrás del escudo de pinos se viste. ayyo aya aya aya ayyo ¡Éste no cae!

En Nonohualco, junto a las tunas del águila, entre flores de cacao se viste ¡Éste no cae!

- Una tendencia marcada hacia el estallido de la voz en fragmentos sonoros a veces inarmónicos que provocan una verdadera glosolalia.

¡Ayya yao! Ah ihui in ti noci

¡Ayya yao! Ah como tú, abuela mía.

(Sahagún 1997, 183)

- Un rico fondo sonoro que acompaña el oleaje verbal cuando el orador busca describir una situación particular. Este oleaje se debe probablemente, por una parte, a la tendencia náhuatl de no realizar aseveraciones perentorias y rodear la dificultad conceptual con circunvoluciones lingüísticas, pero por otra, también a un gusto particular por la ritmicidad del lenguaje sonoro.

Momamantihui, motenuitectihui, motempapahuitihui, tocuileuhtihui tlatlanquiquiztihui, mocuacuecuechotihui.

Se extienden en todas partes, gritan, aúllan, braman como trompetas, sacuden la cabeza

(Códice Florentino, 1979, libro XII, capítulo 15) 
- Una afición por el paroxismo vocal liberador y catártico.

Yyahua yyaya yya aya ayo ohuiya

ayyayya aya yya yo ohuiya

ayya ya ayya ya yyo ohuiya

(Sahagún 1997, 181).

Por sus mismos atributos sonoros y rítmicos, la voz desempeña en la cultura náhuatl una función esencial.

En cualquiera de sus manifestaciones, la modulación y los ritmos del texto náhuatl son verdaderamente viscerales, sugiriendo así que la expresión oral busca, generalmente más allá del lenguaje, la verdad sustancial de sus aseveraciones en el aliento de quien la profiere.

\subsection{El ritmo}

Sin duda alguna, el ritmo es sentido implícito, intraducible en otros términos, y una de las formas expresivas más profundamente arraigadas en el ser. Podemos decir que, más allá de un dinamismo primario, el ritmo aculturado de los antiguos nahuas da, en contrapunto con los sonidos de la naturaleza, una imagen sonora del hombre que lo genera. Conocemos por otra parte la importancia del tambor en el contexto musical y dancístico prehispánico, importancia que deja presentir el papel del ritmo en distintos dominios de la vida y por ende en la expresión oral.

Por las crónicas que nos dejaron los españoles y por las anotaciones de ciertos manuscritos, sabemos que muchos textos precolombinos se cantaban al son de los tambores y su importancia es tal que la instancia de canto se evoca frecuentemente con la metonimia huehuetitlan, "cerca de los tambores".

Además del movimiento que se percibe en el registro verbal del texto, el ritmo fue a veces consignado gráficamente mediante sílabas por los recopiladores, como en el Canto de Nezahualcóyotl: 
Quititi quititi quiti quiti tocoto

tocoti tocototocoti

(Cantares Mexicanos, 1994, fol. 28v)

\subsection{El gesto}

Encontramos entre los indígenas una gama completa de expresión gestual en las funciones de comunicación, de representación o como elemento constitutivo de las instancias coreográfico-musicales de la danza o coreográfico-músico-lingüísticas de enunciación de textos orales. Los españoles habían percibido la importancia del gesto en la cultura náhuatl:

Los indios de esta Nueva España más que otras naciones entienden por meneos y señas, por tener muy vivos los sentidos interiores y exteriores, porque es admirable su imaginativa. (Torquemada 1975, II, 71)

La oralidad no se limita, como el término podría hacerlo creer, a los efectos de la voz; implica todo lo que enmarca y sostiene la comunicación en presencia de uno o varios interlocutores o de un público, desde el simple matiz de una mirada hasta los gestos más elaborados. La instancia de elocución estructura el espacio, y la gestualidad que acompaña la voz opera una semiosis con el texto enunciado, o con la música de un canto.

El gesto es una presencia, una materialidad significante en un espacio productor de sentido. Puede representar la realidad vivida a través de la mimesis total o por la mediación del símbolo, y hacer brotar el sentido de una relación intersemiótica entre él y los elementos lingüísticos y musicales que integran en general la instancia de producción de los textos. También, simplemente rítmico, puede estar correlacionado con la música y la danza. 
La estructuración del comportamiento gestual de los antiguos nahuas estaba íntimamente vinculada con el contexto social de su vida. Los cronistas españoles habían observado ya numerosas prácticas gestuales como el acto de tomar un poco de tierra del suelo para llevarla a la boca cuando se quería garantizar la veracidad de lo que se decía; también el de levantar los brazos y agitar las manos en señal de satisfacción, y otras. Desde los gestos de cortesía hasta las manifestaciones gestuales más significantes, tenemos una continuidad creciente de expresividad corporal.

El gesto ya acompañe, prolongue o sustituya al verbo, está generalmente, si no codificado, por lo menos marcado con fuerza en sus connotaciones por los elementos contextuales de la cultura náhuatl. En este aspecto, constituye un verdadero lenguaje que puede funcionar de manera autónoma o complementaria y hace uso de la imagen y del símbolo.

\subsection{Las pinturas sobre el cuerpo}

Podríamos considerar como una prolongación de las mímicas faciales las pinturas o la tiza con la que se embadurnaban los danzantes en las diferentes instancias de espectáculo. Se trataba generalmente de los atributos cromáticos de los diferentes dioses: amarillo para el dios del fuego Xiuhtecuhtli, azul para Tláloc, rojo para Huitzilopochtli, o del acromatismo del sacrificio: el blanco. El maquillaje, más allá del gesto que hace, es ya la metamorfosis del hombre en su personaje; induce, en los que lo ven, las reacciones psíquicas apropiadas para la situación y da frecuentemente la clave para la interpretación del papel. El maquillaje puede complementar el gesto al ir en el mismo sentido expresivo, o contradecirlo, y así provocar la risa. Es además la mímica, mucho más móvil, la que dará su pleno significado a la pintura facial. 
Si el señor mandaba a los maestros y cantores que cantasen y bailasen el cantar que se llama Cuechtecáyotl, tomaban los atavíos del areito conforme al cantar y se componían con cabelleras y máscaras pintadas, con narices agujeradas y cabellos bermejos, y traían la cabeza ancha y larga como los usan los Cuechtecas y traían las mantas tejidas a manera de red. (Sahagún 1997, 468)

El simbolismo altamente expresivo de las pinturas faciales utilizadas por los indígenas, ya sea en sus rostros o sobre las máscaras que los cubrían en las distintas circunstancias de representación, tenía una gran importancia al nivel de la elocución de los textos. De hecho, como dicha pintura es el jeroglífico mismo del personaje o de la cosa representada, su omisión inevitable en las transcripciones dificultará su aprehensión.

\subsection{La indumentaria}

Así como la pintura corporal, los diferentes elementos que componían el traje de los cantores o danzantes se articulaban sobre una función simbólica primera. Muchos estaban relacionados con los atributos indumentarios de los dioses representados, otros revelaban un simbolismo más oscuro, diluido en la red de connotaciones de la cultura náhuatl.

El traje contenía con frecuencia caracteres predicativos de cualidades específicas que desencadenaban la acción o permitían identificar el o los personajes. Sobre el cuerpo de un danzante, constituía un verdadero jeroglífico cinético:

Bailaban en este día un baile solemnísimo todos vestidos de albas pintadas muy galanas hasta los pies. Pintadas y labradas con unos corazones y palmas de manos abiertas, cifra que daba a entender que con las manos y el corazón pedían buena cosecha por ser ya tiempo de ella. Llevaban en las manos unas bateas de palo y jícaras grandes muy galanas con que 
iban pidiendo remedio y limosna a los ídolos. Las indias que juntamente bailaban llevaban en los faldellines pintadas unas tripas retuertas para denotar el hambre o hartura que esperaban. Morían en el sacrificio aquellas dos hermanas mozas que significaban hambre o hartura. (Durán 1967, I, 280)

Se entiende sin dificultad lo que perderá la síntesis expresiva vocal cuando vengan a desaparecer en la escritura alfabética el esplendor de los trajes, el oro y las plumas, significación simbólica inmanente al personaje que ninguna mediación verbal podría reproducir sin oscurecerla.

\subsection{La danza}

Más allá del aparato gestual que evocamos, la danza constituye la sublimación cinética de la oralidad indígena. En un mundo donde los cinco sentidos del hombre se movilizan en la percepción, donde el espacio está preñado de significado potencial, la danza es un medio imprescindible de afirmación apolínea, o de difusión dionisíaca del hombre en el cosmos.

Resultaría vano el intento de rastrear, a través de los documentos disponibles, las distintas modalidades coreográficas que brotan de estas dos tendencias esenciales. Nos conformaremos con describir los géneros dancísticos que las ilustran: el macehualiztli y el netotiliztli:

En esta lengua de Anáhuac, la danza o baile tiene dos nombres: el uno es macehualiztli, y el otro netotiliztli. Este postrero quiere decir propiamente baile de regocijo, con que solazaban y tomaban placer los indios en sus propias fiestas, así como los señores y principales en sus casas y en sus casamientos. Y cuando así bailan y danzan dicen netotilo: "bailan o danzan"; netotiliztli: "baile o danza". El segundo y principal nombre de la danza se llama macehualiztli, que propiamente quiere decir "merecimiento", macehualo quiere decir "merecer". Tenían este baile 
por obra meritoria, ansí como decimos merecer uno en las obras de caridad, de penitencia, y en las otras virtudes hechas por buen fin. De este verbo macehualo viene su compuesto tlamacehualo, por "hacer penitencia o confesión", y estos bailes más solemnes eran hechos en las fiestas generales y también en las particulares de sus dioses, y hacíanlos en las plazas. (Motolinía, apud Garibay 1971, 82)

La distinción que establece Motolinía entre el macehualiztli y el netotiliztli como bailes respectivamente de "merecimiento" y de "regocijo" se aplica por supuesto a la danza tal y como la perciben los frailes a mediados del siglo XVI, cuando el generador socio-religioso prehispánico ha dejado de funcionar. Más que oponer un baile religioso a otro supuestamente profano nos parece pertinente distinguir una danza espectacular estructurada formalmente como ofrenda a los dioses ( $m a-$ cehualiztli) de otra en la que el gozo, es decir, el placer de los sentidos, arrastra a la colectividad en una ebriedad motriz.

A veces se usaban alucinógenos para exacerbar el efecto de los ritmos:

La primera cosa que se comía [...] eran unos honguillos que se llamaban nanácatl que emborrachan y hacen ver visiones [...] aquellos honguillos se comían con miel y cuando ya se empezaban a calentar con ellos, comenzaban a bailar y algunos cantaban y algunos lloraban porque ya estaban borrachos con los honguillos. (Sahagún 1997, 504-505)

En una modalidad o en otra, el cuícatl era, según la expresión de los mismos religiosos españoles, "cosa muy de ver", pero también de saborear, de oler y de palpar.

\subsection{La música}

El concepto abstracto de música, tal y como lo entendemos hoy en día, no existe en el México prehispánico. El término 
náhuatl correspondiente: cuícatl, designa un todo expresivo en el cual se funden la danza, la palabra cantada y una amplia gama de efectos sonoros ya sean musicales o no. De hecho, el signo ideográfico que simboliza la palabra es el mismo que para la música: una vírgula a veces realzada con una flor. Este hecho es muy significativo puesto que funde la palabra y el arte músico/dancístico en un mismo origen de la expresión.

Palabra y música comulgan verdaderamente en una misma esencia afectiva por regresión hacia este punto del origen de todo sentido, conceptual tanto como expresivo, hacia este manantial común de donde brotan música y poesía. (Court 1976, 264)

En su acepción más amplia, la vírgula de los códices mexicanos designa en efecto, más allá de la palabra o de la música, el "espíritu", ihíyotl, que tiene, como en el término griego pneuma, o en el latín spiritus, la connotación de aliento, de soplo.

En tiempos prehispánicos, la música no se distingue claramente de un registro sonoro más amplio que incluye todos los ruidos. Éstos son la manifestación sonora de distintas entidades naturales que el hombre buscará reproducir para agradar a los dioses o para inducir mágicamente fenómenos naturales como la lluvia, la fecundidad, etc. Están vinculados por analogía con las diversas manifestaciones de la naturaleza y los efectos que producen. Un bastón lleno de semillas induce la lluvia, el silbido evoca a Ehécatl Quetzalcóatl, etcétera. Así como tienen que proveer el templo de leña e incienso para el fuego sagrado, y realizar autosacrificios penitenciales, los sacerdotes deben producir continuamente efectos sonoros que constituyen una ofrenda al dios.

Velaban con muchas hogueras de fuego que hacían y bocinas y cuernos que tañían haciendo gran estruendo y ruidos con estos instrumentos. (Torquemada 1976, III, 423) 
La música acompañaba los distintos acontecimientos socioculturales de la colectividad mexica. Una melodía solemne ponía fin a los partidos de pelota entre los reyes, y los caracoles se hacían oír en los momentos cumbre del ritual. En la variante gladiatoria del sacrificio, por ejemplo, unos efectos sonoros dramatizaban la herida de la víctima:

Mas empero, como el uno estaba armado y el otro, desnudo, y el otro tenía su espada de filos, y el otro de solo palo, a pocas vueltas, le hería o en la pierna, o en el muslo, o en el brazo, o en la cabeza y así, luego en hiriéndole, tañían las bocinas y caracoles y flautillas y el preso se dejaba caer. (Torquemada 1976, III, 423)

Más allá de su función mítica, el sonido vale por sí mismo, por su timbre particular y se integra en un conjunto dancístico-musical estructurado. En la mayoría de las instancias de cuícatl, los danzantes llevaban sartas de cascabeles enroscadas a los tobillos o a las manos, además de los instrumentos que tañen. Lo visual, lo rítmico y lo sonoro se fundían entonces en una explosión de sentido estético-ritual.

\section{El espíritu y la letra: la lectura de un texto oral náhuatl} trascrito

El texto náhuatl hoy recluido en la página blanca de un libro, en una versión alfabética impresa, fue un día un conjunto de palabras, gestos, sonidos, fragancias y colores que se fundían en el crisol de una instancia específica de enunciación para que fraguara un sentido. El tenor sinestésico de la expresión oral náhuatl prehispánica, su irreductibilidad a la palabra, hacen que la parte verbal del texto que hoy se lee, sea insuficiente para una aprehensión plena de su forma y de su contenido. Sin embargo, sin esta transcripción nada habría permanecido 
de la oralidad náhuatl, por lo que las palabras que yacen en los manuscritos constituyen verdaderas "reliquias" literarias que una lectura adecuada puede revitalizar.

La importancia de la palabra en la expresión oral depende del género considerado. En el huehuetlahtolli "palabra de los ancianos", el machiotlahtolli "palabra-modelo" (los proverbios), el zazanilli "adivinanzas", trasciende el semantismo de la palabra, la construcción frástica y la retórica por lo que el sentido será aprehensible mediante una lectura dinámica que pueda restituir las afinidades sonoras del original náhuatl.

En cambio, la índole expresiva de otros géneros implica un conocimiento de circunstancias y contextos específicos en los que se enunciaba, cantaba o bailaba el texto, así como una reconstrucción imaginaria, con base en las fuentes disponibles, de su modalidad oral de expresión. Es preciso evitar una lectura "gramatical" del texto y abrir las mallas de la red linguística para imaginar, de acuerdo con el semantismo del texto, los contextos y las circunstancias previamente determinados, los gestos, gritos, compases dancísticos, etcétera, que podrían haber separado las palabras y las frases que hoy forman una unidad gráfica en el manuscrito.

La lectura (y la traducción implícita o explícita) debe evitar "zurcir" el tejido verbal aparentemente desgarrado por anacolutos, elipsis, síncopas, y más generalmente por una parataxis manifiesta ya que estas "rupturas" remiten a una enunciación oral dramatizada. Para dar tan sólo un ejemplo, en un teocuícatl ${ }^{9}$ dedicado a Ixcozauhqui, un dios del fuego, la traducción al castellano del náhuatl por Ángel María Garibay muestra un afán de coherencia sintáctica y sintagmática que desvirtúa lo que debe haber sido la expresión original. La frase moteicnelil mahuizt$l i{ }^{10}$ es traducida como "(logran los príncipes) hacerse dignos de gloria" (Garibay 1958, 85), ignorando el anacoluto que expresa

${ }^{9}$ Canto de dioses.

${ }^{10}$ Códice Florentino, 1979, libro II, Apéndice. 
un cambio brusco de construcción gramatical y sugiere el tono enfático, apoteótico, teatral de la frase. Una traducción más afín de la versión oral podría ser: "tu merecimiento: la gloria", la cual si bien no tiene un contenido distinto, determina sin embargo otra forma y por lo tanto, otro sentido.

En términos generales, la lectura de un texto oral náhuatl transcrito deberá dar cabida semántica a elementos expresivos que el aparato gráfico español de recopilación no pudo retener, pero que existieron manifiestamente. Sólo considerando los factores rítmicos, sonoros, visuales, dramáticos y otros parámetros expresivos y receptivos puede llegarse a una aprehensión correcta del sentido del texto.

\section{Conclusión}

Los efectos de la voz, el rico atuendo estilístico y fonético de la palabra, la proyección espacial del gesto generalmente sublimado en la danza, la presencia altamente significativa de un esplendoroso vestuario y de un maquillaje preñado de sentido cromático, los ritmos frenéticos de los tambores o el suspiro melancólico de los silbatos, toda esta orgía de potencial expresivo contenida en la fecunda matriz de un espacio sagrado constituía una sustancia en la que los indígenas nahuas esculpieron formalmente su presencia oral en el mundo.

De esta profusión semiótica, los manuscritos españoles conservaron exclusivamente el elemento verbal, empobrecido además por los avatares de la recopilación y de la transcripción alfabética. A partir de un simple manuscrito, será preciso intentar reconstituir, mediante la imaginación, la riqueza espectacular de la oralidad mexicana precolombina. 


\section{REFERENCIAS}

Cantares Mexicanos (Ms. en náhuatl), 1994. Manuscrito de la Biblioteca Nacional de México, México, Instituto de Investigaciones Bibliográficas.

Códice Florentino (Testimonios de los informantes de Sahagún), 1979. Facsímil elaborado por el Gobierno de la República Mexicana, México, Giunte Barbera.

Court, Raymond, 1976. Le musical. Essai sur les fondements anthropologiques de l'art, Paris, Klincksieck.

Durán, Diego, 1967. Historia de las Indias de Nueva España e islas de Tierra Firme, México, Porrúa, 2 vols.

GARIBAY, Ángel María, 1958. Veinte Himnos sacros de los nahuas, México, UNAM.

—,1971. Historia de la literatura náhuatl, tomo I, México, Porrúa, Johansson, Patrick, 1999. "La Historia General de Sahagún. De la voz indígena al capítulo 15 del libro XII: las tribulaciones editoriales de un texto", Estudios de Cultura Náhuatl 29, 209-241.

—, 2002. Ritos mortuorios nahuas precolombinos, Puebla, Secretaría de Cultura del Estado de Puebla.

—, 1998. "Cantos de cacería en su matriz mítico-ritual", Literatura Mexicana 10-2, 313-341.

Mendieta DE, fray Gerónimo, 1980. Historia eclesiástica Indiana, México, Porrúa.

PAz, Octavio, 1981. El arco y la lira, México, Fondo de Cultura Económica.

Sahagún, fray Bernardino de, 1997. Historia General de las Cosas de la Nueva España, México, Porrúa.

Torquemada, Fray Juan de, 1992. Monarquía Indiana, 7 tomos, México, Instituto de Investigaciones Históricas, UNAM.

Zumthor, Paul, 1983. Introduction à la poésie orale, Paris, Editions du Seuil. 